4. Mohr FW, Falk V, Krieger H, Likungu J, Abu Aisha N, Coppola $\mathrm{R}$, et al. IMA-graft patency control by thermal coronary angiography during coronary bypass surgery. Eur J Cardiothorac Surg 1991;5:534-41.

5. Falk V, Walther T, Philippi A, et al. Thermal coronary angiography for intraoperative patency control of arterial and saphenous vein coronary artery bypass grafts: results in 370 patients. J Card Surg 1995;10:147-60.

6. Emery RW, Emery AM, Flavin TF, Nissen M, Mooney MR, Arom KV. Revascularization using angioplasty and minimally invasive techniques documented by thermal imaging. Ann Thorac Surg 1996;62:591-3.

\title{
TROPONIN I RELEASE DURING MINIMALLY INVASIVE CORONARY ARTERY SURGERY
}

\author{
I. Birdi, FRCS, M. Caputo, MD, J. A. Hutter, FRCS, A. J. Bryan, FRCS, and G. D. Angelini, FRCS, \\ Bristol, United Kingdom
}

Revascularization of the left anterior descending artery (LAD) without cardiopulmonary bypass through a left anterior small thoracotomy (LAST) ${ }^{1}$ is increasing in popularity. This has been driven partly by current trends toward cost containment, ${ }^{2}$ despite the fact that the effectiveness of the surgical procedure both in terms of early and long-term outcome are still under evaluation. One concern is the potential risk of ischemic damage to the warm, metabolically active myocardium during occlusion of the LAD. To investigate this further, we measured troponin I, a highly specific marker for the detection of myocardial injury, ${ }^{3}$ in 14 selected patients ( 13 men, mean age 58 years) undergoing LAD revascularization via the LAST operation. These were compared with a control group of 14 patients (12 men, mean age 57 years) undergoing myocardial revascularization of one or two arteries with the use of normothermic cardiopulmonary bypass and warm blood cardioplegia. All patients underwent elective operations and had well-preserved left ventricular function. Blood samples were collected for troponin I estimation before the operation and $4,12,24,36$, and 48 hours after the operation.

The two groups were similar with respect to preoperative characteristics. No patient had clinical or electrocar-

From the Bristol Heart Institute, University of Bristol, Bristol Royal Infirmary, Bristol, United Kingdom.

Received for publication April 1, 1997; accepted for publication April 9, 1997.

Address for reprints: Gianni D. Angelini, FRCS, British Heart Foundation, Professor of Cardiac Surgery, Bristol Heart Institute, Bristol Royal Infirmary, Bristol BS2 8HW, United Kingdom.

J Thorac Cardiovase Surg 1997;114:509-10

Copyright (C) 1997 by Mosby-Year Book, Inc.

$0022-5223 / 97 \$ 5.00+0 \quad \mathbf{1 2 / 5 4 / 8 2 6 7 8}$ diographic evidence of perioperative myocardial infarction. Cardiopulmonary bypass time in the control group was $49 \pm 8$ minutes during which time a mean of $1.5 \pm 0.5$ distal anastomoses were performed. The ischemic times in the control and LAST groups were $24 \pm 5$ minutes and $37 \pm 8$ minutes, respectively. Preoperative troponin I concentrations were undetectable in both groups. In the control group, a significant rise in troponin I concentrations was observed 4 hours after the operation; the peak occurred at 12 hours, and the concentration remained significantly higher than preoperative levels even at 48 hours $(p<0.006)$. In the LAST group, a small but significant rise in troponin I concentration was noted at 4 hours $(p<0.02)$, but the levels were considerably lower

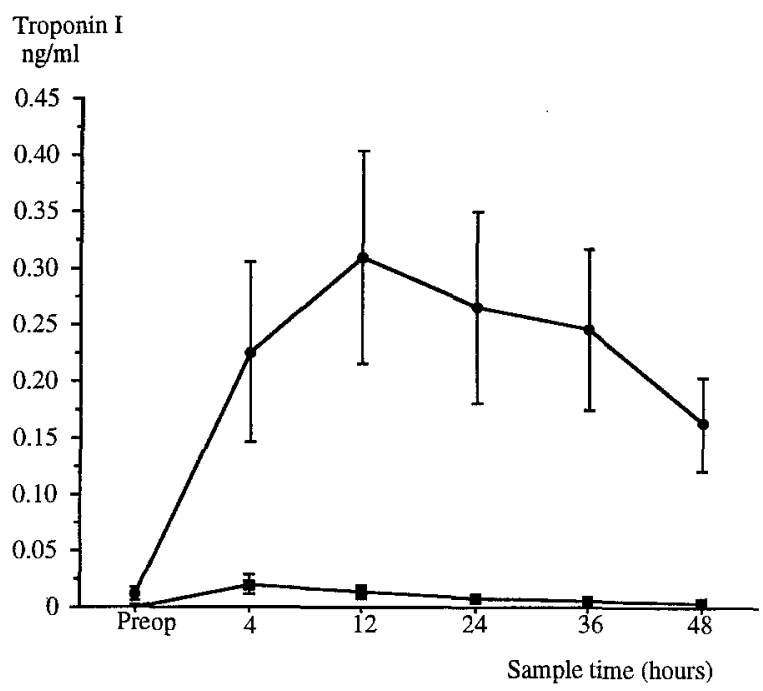

Fig. 1. Troponin I release after coronary artery surgery. 口, Conventional CABG; $\bullet$, last operation. 
than in the control group and declined rapidly thereafter (Fig. 1).

Our data suggest that ischemic injury to the myocardium as indicated by troponin I release may not be important after occlusion of the LAD as part of the LAST procedure. Furthermore, troponin I release was significantly less than that produced by the global insult resulting from conventional operations. These observations provide encouragement for the future development of minimally invasive coronary surgery in modern cardiac surgical practice.

\section{REFERENCES}

1. Calafiore A, Angelini G. Left anterior small thoracotomy (LAST) for coronary artery revascularisation. Lancet 1996; 347:263-4.

2. Westaby S, Benetti F. Less invasive coronary artery surgery: consensus from the Oxford meeting. Ann Thorac Surg 1996; 62:924-31

3. Etievent J, Chocron S, Toubin G, et al. Use of cardiac troponin I as a marker of perioperative myocardial ischemia. Ann Thorac Surg 1995;59:1192-4. 